\title{
An innovative method to build support structures with a pulsed laser in the selective laser melting process
}

\author{
Jamasp Jhabvala $\cdot$ Eric Boillat • \\ Cédric André · Rémy Glardon
}

Received: 22 December 2010 / Accepted: 13 June 2011 / Published online: 7 July 2011

(C) Springer-Verlag London Limited 2011

\begin{abstract}
In selective laser melting machines, continuous laser are usually used to melt the powder. The support structures, which are inevitable when dealing with elaborated pieces, necessitate a complex design by CAD in order to be easily removed. This paper propose an innovative laser manufacturing method by combining pulsed and continuous modes of radiation. Continuous radiations are used for the object-to-build itself, in order to guarantee the requested mechanical properties. Pulsed radiations are used to build the support structures. The resulting support structures have sufficient mechanical properties to withstand the deposition system and to evacuate heat, and are easy to remove from the denser parts. This building method reduces drastically time to market since the same laser can be used in two modes and because pulsed radiation allows very high scanning speed with high power during the building of support structures.
\end{abstract}

Keywords Selective laser melting - Pulsed laser • Support structures $\cdot$ Nd-YAG $\cdot$ Microstructures

J. Jhabvala $(\bowtie) \cdot$ E. Boillat $\cdot$ R. Glardon

Laboratoire de Gestion et Procédés de Production,

IGM-STI-EPFL, Station 9, 1015 Lausanne, Switzerland

e-mail: jamasp.jhabvala@a3.epfl.ch

C. André

Laboratoire de Mécanique et Génie Civil,

University of Montpellier II, UMR CNRS

5508, Place Eugène Bataillon, CC048,

34095 Montpellier, France

\section{Introduction}

Selective laser melting is an additive manufacturing process coming from the principles and applications of rapid prototyping and rapid tooling $[1,2]$. In most additive manufacturing techniques, support structures are needed when the object to build has overhangs of more than $30^{\circ}$ [3-7]. An example of support structures is shown in Fig. 1 (support structures in dark grey). They have three functions:

- Avoid the collapsing of the object due to gravity during construction.

- Avoid the destruction or displacement of the object by the powder deposition system (blade, hopper, etc.).

- Ensure regular thermal conditions in the consolidation zone, for example by evacuating heat to avoid intense local fusion, and withstand residual thermal stresses [8].

For selective laser melting, the last two functions are the most important. The first one can be ignored since the object is built on a supporting powder bed.

The support structures are, thus, inevitable but pose many problems.

1. Time and material are needed to build them.

2. Their creation requires complex and timeconsuming actions in CAD design. Commercial softwares offer help in creating support structures, but they are often unadapted to complex shapes and overestimated in terms of thickness.

3. After the end of the construction, the support structures have to be taken off the finished object. This process is difficult because access is often limited. It 
Fig. 1 CAD model of a 3D object requiring support structures (the support structures appear in dark grey)

also leaves marks on surfaces which can be incompatible with aesthetic requirements.

To avoid the last disadvantage, the support structures are usually designed in a way to minimize contact with the object [9-11]. Since the obtained structure is more fragile, a compromise has to be found.

\section{State of the art}

When using pulsed laser in selective laser melting, only the surface of the powder particles is molten and consolidation can be achieved at much lower average power. In particular, there is almost no loss of energy within the grains. Liquid bridges appear between the powder particles and are responsible for the bonding. The mechanical properties of the final part depend on the shape of these bonds. The goal of many studies was to understand how the evolution of the liquid bridges (also called necks) was influenced by the laser parameters [12-15].

\subsection{Consolidation process}

The global consolidation process is essentially driven by the minimization of the total surface energy [16]. Under laser heating, the material tends to group in a sphere. When too much energy is given, balling appears $[17,18]$.

The kinetics of the material reorganization is slowed down by viscous effects and material re-solidification. Because of these two phenomena, the control of the quantity of molten material and of its lifetime is essential to ensure a strong microscopic bounding and a good macroscopic precision of any part made by pulsed lasers [15]. The quantity of liquid and the time it takes to get back to solid state can be influenced by the laser parameters. It can be shown that metallic particles essentially undergo superficial melting under short laser pulses (Fig. 2) [19]. The growing of the necks can be controlled by adjusting the pulse frequency [13]. The use of pulsed lasers is excellent for accuracy because the liquid has no time to spread. It only forms bonding between the particles. But the obtained objects are porous and their mechanical properties are much inferior to dense objects made with continuous lasers. The idea of this method is to use this drawback as an advantage for building support structures. Lasers in continuous mode are able to produce degraded mechanical properties
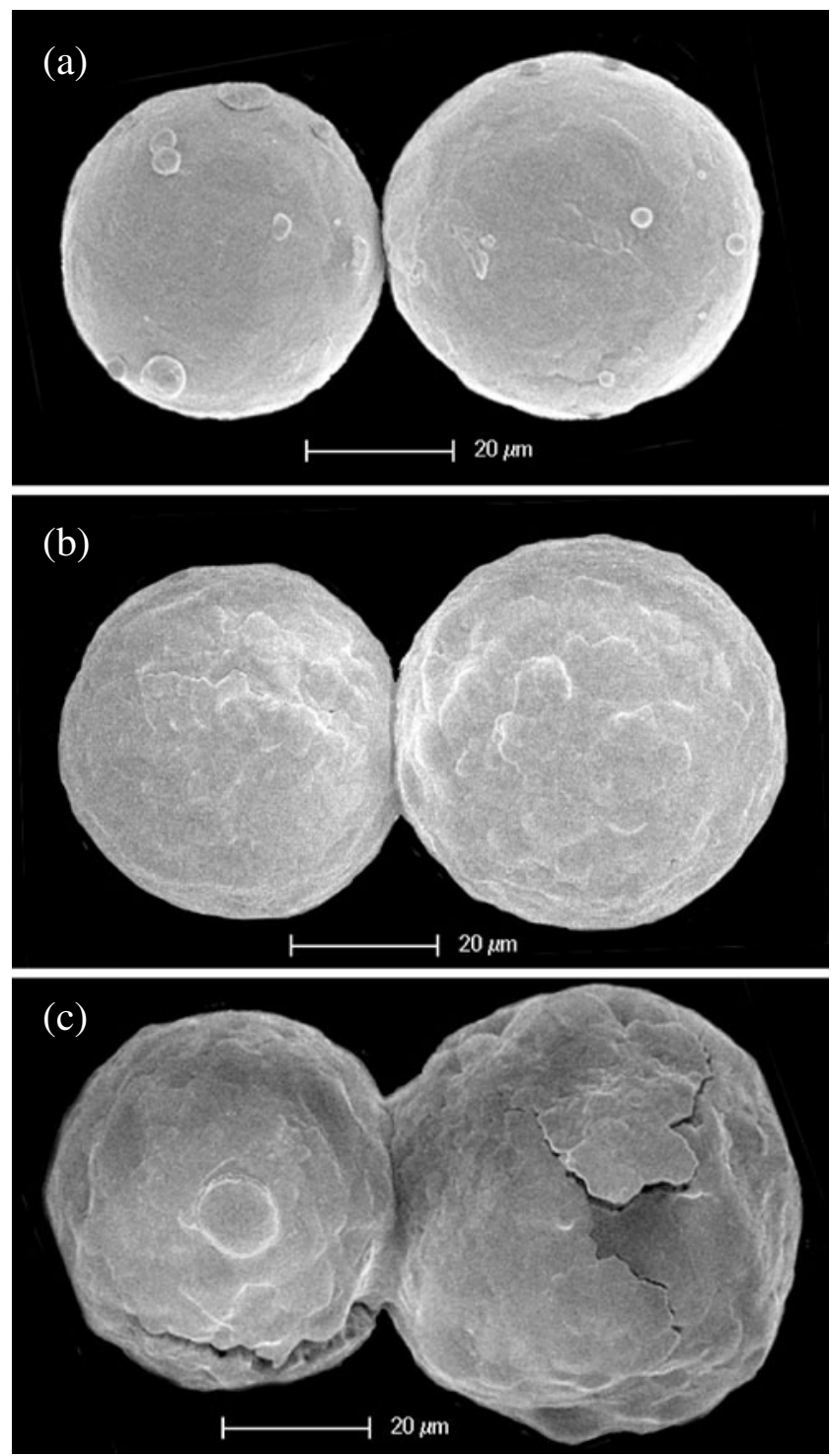

Fig. 2 Growing of a neck between two powder particles subjected to laser irradiation; the growing of the neck can be controlled by adjusting the pulse frequency 
as well when using sub-optimal build parameters, but the target of usable parameters is very narrow and the porosity hard to control. Furthermore, the speed has to be set precisely to obtain the desired structures, while pulsed radiation allows to use very high speed. A pulsed radiation is able to melt the surface of the grains at a lower energy than continuous radiation (see Fig. 3).

\section{Experimental setup}

\subsection{SLM system}

The SLM system used in this study is an experimental platform developed in the lab. A complete description of it can be found in [13]. The laser is a $\mathrm{Nd} / \mathrm{YAG}$ (Quantronix Condor) operating with an average power of $100 \mathrm{~W}$. It can be used either in continuous mode or in pulsed mode (repetition rate, 2 to $50 \mathrm{kHz}$ and pulse duration: $\sim 225 \mathrm{~ns}$ ). In normal mode (multimode), the focal beam radius is $\sim 150 \mu \mathrm{m}\left(\mathrm{M}^{2}=13\right)$.

\subsection{Powders used}

The powders used in this study are:

- A 316L stainless steel powder supplied by Sulzer Metco AG. It is distributed between 11 and $45 \mu \mathrm{m}$.

- A 99.9\% pure silver powder supplied by Nippon Atomized Metal Powders Corporation. It is distributed around $10 \mu \mathrm{m}$.

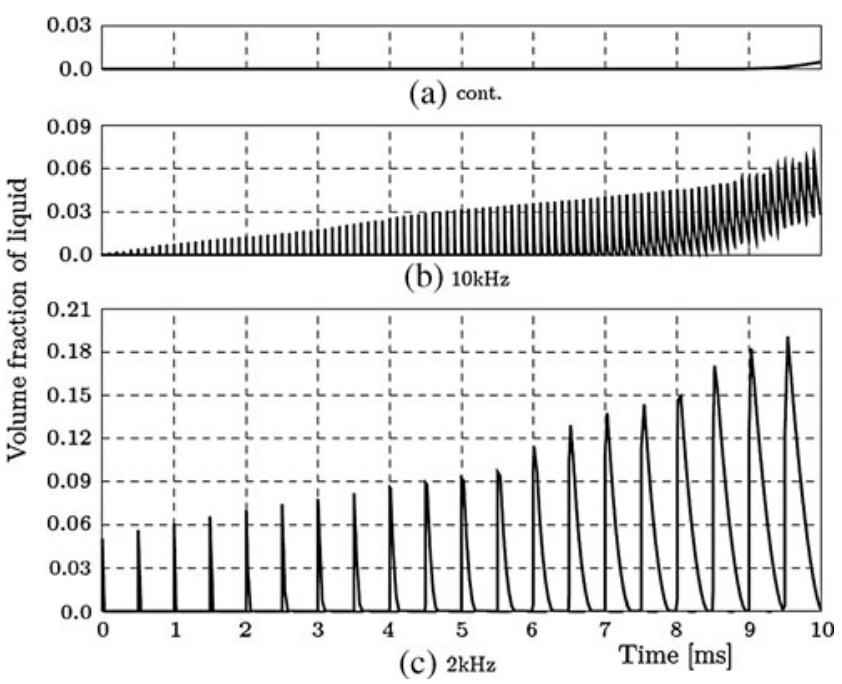

Fig. 3 Evolution of the quantity of liquid formed for different repetition rates (from Ref. [13])

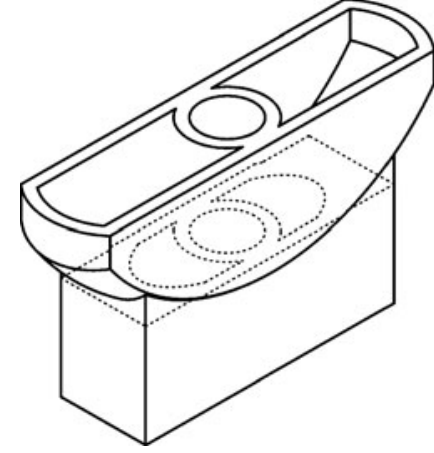

(a)

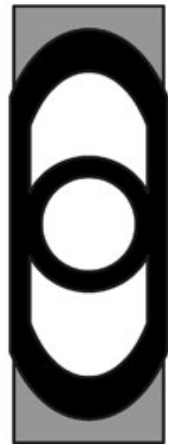

(b)
Fig. 4 Schematic representation of a 3D object requiring a block support structure. a $3 \mathrm{D}$ view and $\mathbf{b}$ top view of one layer: the laser will scan the object surface in continuous mode (in black) and the support structure surface in pulsed mode (in grey)

\subsection{Description of the building}

Figure 4a shows an example of an object with a block support structure. Note that the structure does not need to be a plain block since it takes time to scan.

On Fig. $4 b$ one can see a precise layer during the building of this part. The detailed procedure is the following :

1. A layer of powder is deposited on all of the bed

2. The object (black) is scanned by the laser in continuous mode

3. The support structure (grey) is scanned by the laser in pulsed mode

Then the same procedure is repeated for all the layers. At the end of the building process, the support structures are removed by sandblasting or by an equivalent process.

\section{Results}

\subsection{Produced microstructures}

A preliminary study was conducted in order to determine which kind of microstructures were achievable. In [12], more than 70 sets of laser parameters have been investigated on monolayers and the resulting microstructures were classified in terms of surface fraction of solid (directly correlated to mechanical properties) and equivalent perimeter (correlated to the coarseness and/or fineness of the microstructure)

The powder used is $316 \mathrm{~L}$ stainless steel (see Section 3.2). By adjusting the pulse frequency as well as the 


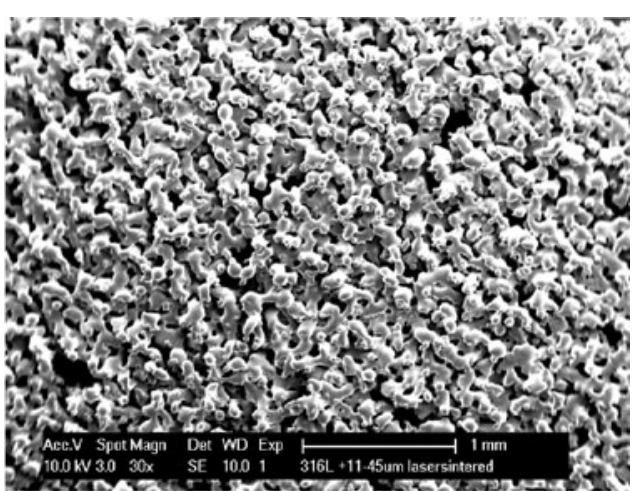

(a) $\mathrm{P}=6.7 \mathrm{~W}, \mathrm{f}=5 \mathrm{kHz}, \mathrm{v}=100 \mathrm{~mm} / \mathrm{s}$

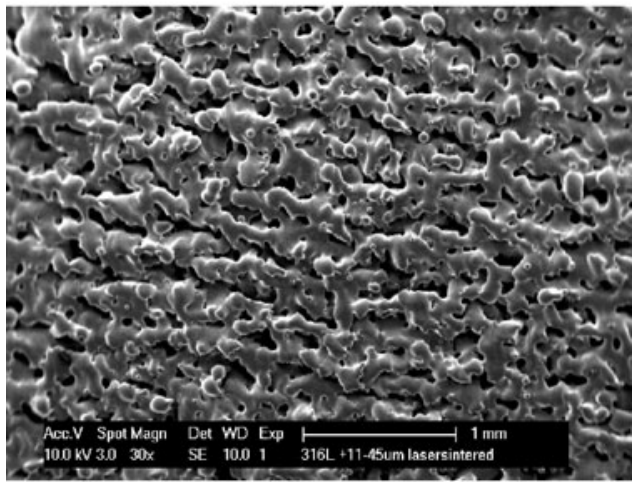

(b) $\mathrm{P}=8.7 \mathrm{~W}, \mathrm{f}=10 \mathrm{kHz}, \mathrm{v}=65 \mathrm{~mm} / \mathrm{s}$

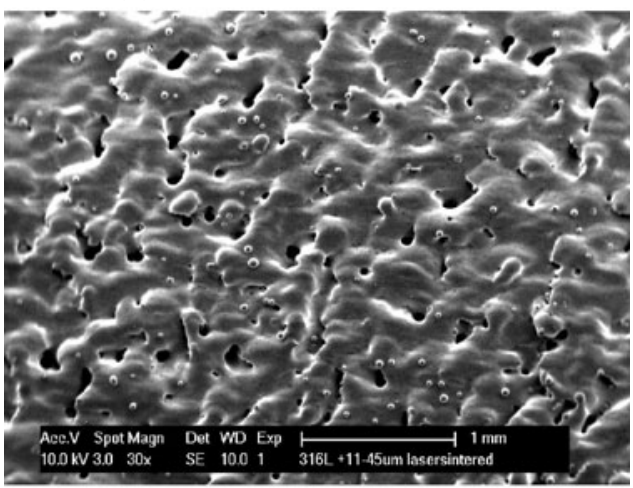

(c) $\mathrm{P}=8.7 \mathrm{~W}, \mathrm{f}=10 \mathrm{kHz}, \mathrm{v}=25 \mathrm{~mm} / \mathrm{s}$

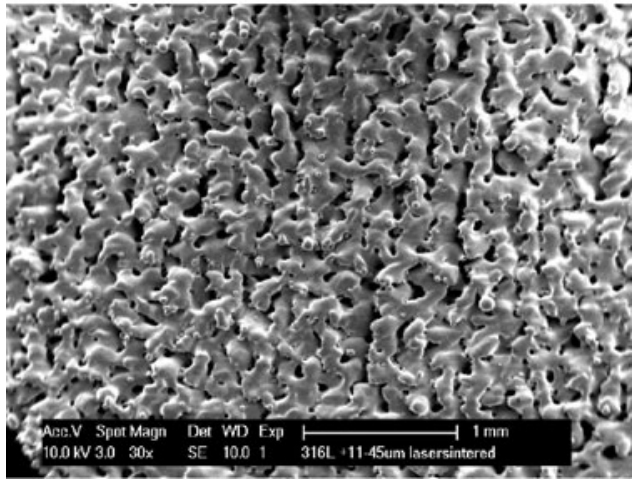

(d) $\mathrm{P}=6.0 \mathrm{~W}, \mathrm{f}=20 \mathrm{kHz}, \mathrm{v}=30 \mathrm{~mm} / \mathrm{s}$

Fig. 5 Examples of monolayers microstructures made by pulsed laser consolidation of type $316 \mathrm{~L}$ stainless steel powders. By adjusting the pulse frequency as well as the average power and the scanning speed, different type of microstructure are achievable power and scanning speed, different type of microstructure can be achieved (see Fig. 5).

These results can be transposed to multilayers 3D objects. By adjusting the laser parameters, one can build porous support structures which are easy to remove but strong enough to withstand the layer deposition and the thermal effects, as we shall see in Section 4.2.

\subsection{Example of a piece with support structures}

The watch clasp of Fig. 6 was made out of pure silver (see Section 3.2).

It can be seen on Fig. 7 that the consolidation of the object is very different between the object in continuous mode (a) and the support structures part in pulsed mode (b). The mechanical properties are different as well. The support structures (here grill-shaped ones) are more fragile but penetrate the layer beneath to
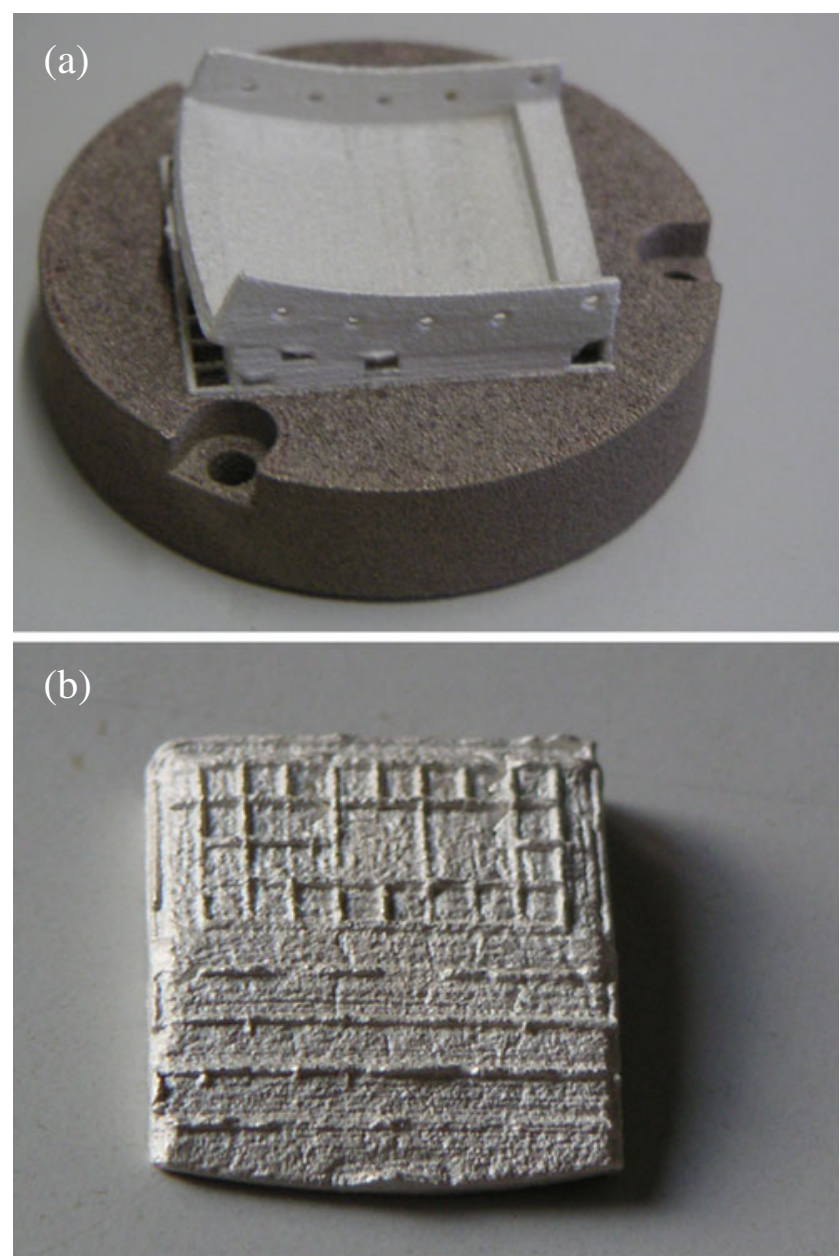

Fig. 6 Silver watch clasp with support structures (a) and after removing of the support structures by sandblasting (b) 


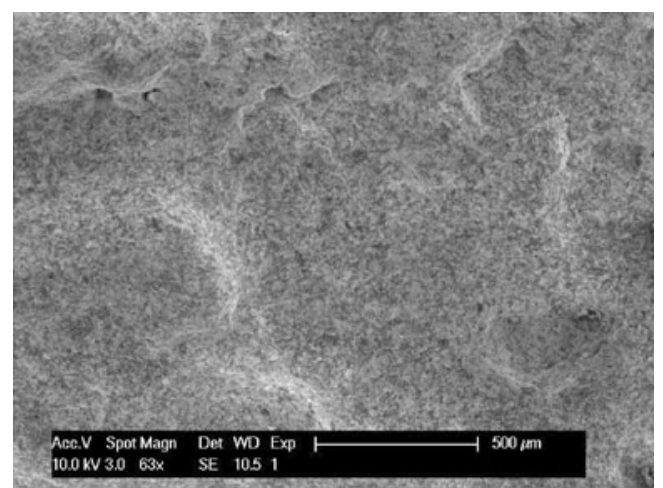

(a) $\mathrm{P}=100 \mathrm{~W}, \mathrm{CW}, \mathrm{v}=5 \mathrm{~mm} / \mathrm{s}$

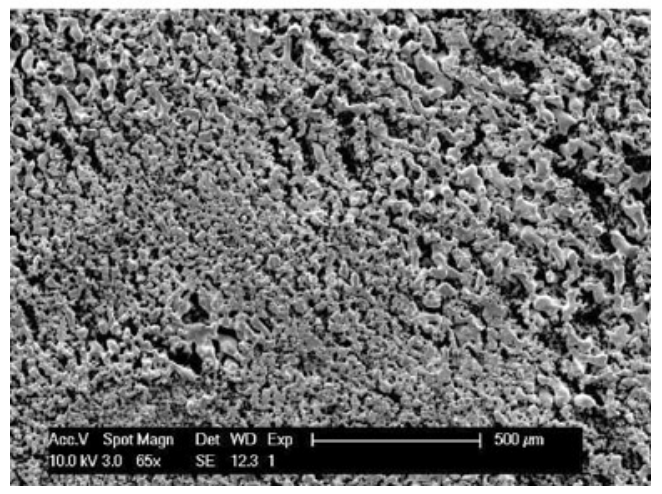

(b) $\mathrm{P}=100 \mathrm{~W}, \mathrm{f}=5 \mathrm{kHz}, \mathrm{v}=10 \mathrm{~mm} / \mathrm{s}$

Fig. 7 Microstructure of silver part made by continuous mode (a) and pulsed mode (b)

enough extent to prevent component distortion under thermal stresses. After the fabrication, they can be easily dissociated from the object by sandblasting (see Fig. 6). The strength of the object is enough to withstand the impact when the support structures are removed. As usual with SLM, post-treatment of the piece is needed to reach the desired surface roughness. It is facilitated by the porosity of the support structures.

The same results can be obtained for all materials since the porous structures produced by pulsed mode are in general more fragile than a dense part produced by continuous mode. As far, experiments on pure silver (see Fig. 7), stainless steel (see Fig. 5), alloyed silver, alloyed gold, and cobalt chromium alloy (see Fig. 8) have been carried out. By adjusting the laser parameters for each powder, targets were found where the support structures are easy to remove but strong enough to resist to layer deposition and thermal effects. So far the scanning speed for pulsed radiation used in these experiments is small, but it can be easily increased, since the particles melt and solidify between each pulse [13]. By increasing the scanning speed and the frequency, the same microstructural results will be found.

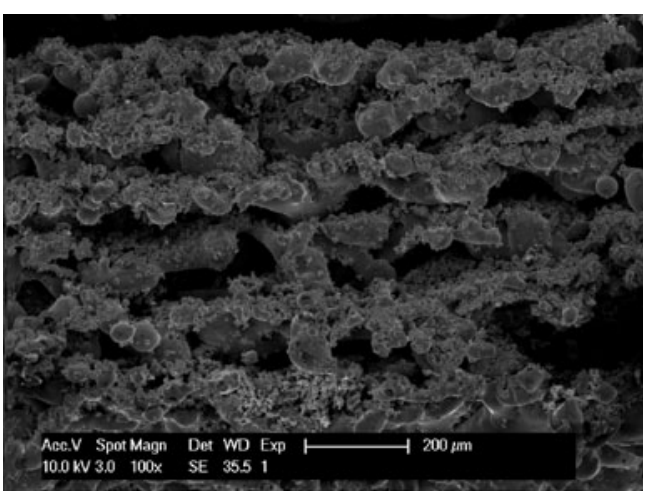

(a) $\mathrm{P}=57 \mathrm{~W}, \mathrm{f}=5 \mathrm{kHz}, \mathrm{v}=800 \mathrm{~mm} / \mathrm{s}$

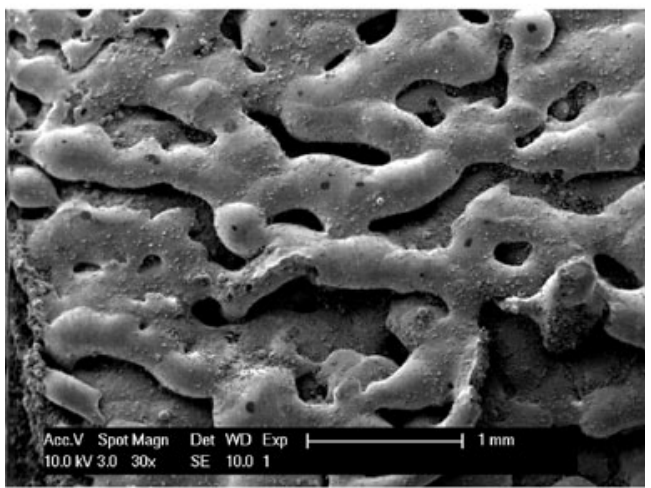

(b) $\mathrm{P}=98 \mathrm{~W}, \mathrm{f}=5 \mathrm{kHz}, \mathrm{v}=30 \mathrm{~mm} / \mathrm{s}$

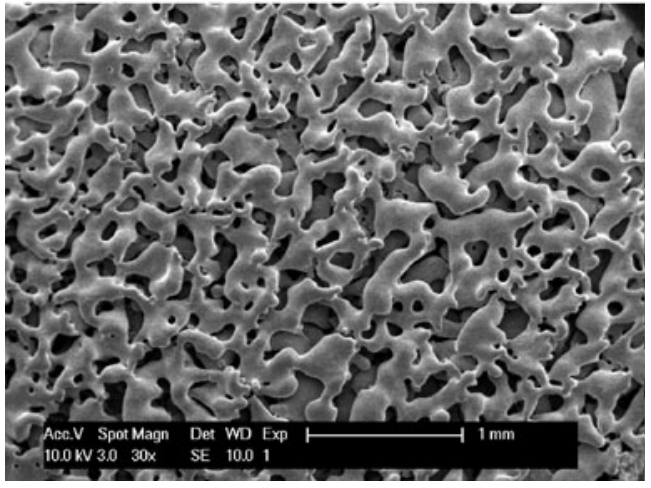

(c) $\mathrm{P}=17 \mathrm{~W}, \mathrm{f}=5 \mathrm{kHz}, \mathrm{v}=10 \mathrm{~mm} / \mathrm{s}$

Fig. 8 Microstructure of cobalt chromium part (a) alloyed silver part (b) and alloyed gold part (c)

\section{Conclusions}

This new way to build support structures is a promising method to avoid most of the disadvantages of the usual structures. The CAD file is easy to generate, the fabrication facilitated by the possibility to use simple-shaped structures and the removing is simple and safe. By using pulsed radiation, the scanning speed can be increased and the global building time decreased. In addition, the development of the technique presented this the paper should be facilitated in the future by the new generation of pulsed fibre lasers. 
Acknowledgments We are thankful to the Interdisciplinary Centre for Electron Microscopy (EPFL) to give us access to electron microscopes and to Corine Zuber at the Service des Relations Industrielles (EPFL) for her precious advices.

\section{References}

1. Chua CK, Liu A, Leong KF (2008) State of the art in rapid metal manufacturing. In: 3rd international conference on rapid prototyping and manufacturing and 2nd international conference for bio-manufacturing

2. Levy GN, Schindel R, Kruth JP (2003) Rapid manufacturing and rapid tooling with layer manufacturing $(\mathrm{lm})$ technologies, state of the art and future perspectives. CIRP Ann Manuf Technol 52(2):589-609

3. Huang X, Ye C, Wu S, Guo K, Mo J (2009) Sloping wall structure support generation for fused deposition modeling. Int J Adv Manuf Technol 42:1074-1081

4. Liu F-H, Liao Y-S (2010) Fabrication of inner complex ceramic parts by selective laser gelling. J Eur Ceram Soc 30(16):3283-3289

5. Nee AYC, Fuh JYH, Miyazawa T (2001) On the improvement of the stereolithography (sl) process. J Mater Process Technol 113(1-3):262-268

6. Vandenbroucke B, Kruth J-P (2007) Selective laser melting of biocompatible metals for rapid manufacturing of medical parts. Rapid Prototyping J 13(4):196-203

7. Zhou W, Li D, Wang H (2010) A novel aqueous ceramic suspension for ceramic stereolithography. Rapid Prototyping J 16(1):29-35

8. Kruth JP, Mercelis P, Van Vaerenbergh J, Craeghs T (2008) Feedback control of Selective Laser Melting.In: Bartolo et al (eds) Virtual and rapid manufacturing, pp 521-527
9. Zaeh M, Branner G (2010) Investigations on residual stresses and deformations in selective laser melting. Prod Eng 4(1):35-45

10. Gebhardt A, Schmidt F-M, Hotter J-S, Sokalla W, Sokalla P (2010) Additive manufacturing by selective lasermelting the realizer desktop machine and its application for the dental industry. Physics Procedia 5(part 2):543-549

11. Wong M, Owen I, Sutcliffe CJ, Puri A (2009) Convective heat transfer and pressure losses across novel heat sinks fabricated by selective laser melting. Int $\mathrm{J}$ Heat Mass Transfer 52(12):281-288

12. André C (2007) Modélisation quantitative du procédé de frittage sélectif par laser: relation paramètres/microstructure. Ph.D. thesis, EPFL, p 3716

13. Jhabvala J (2010) Study of the consolidation process under macro- and microscopic thermal effects in selective laser sintering and selective laser melting. Ph.D. thesis, EPFL, p 4609

14. Kruth J-P, Levy G, Klocke F, Childs THC (2007) Consolidation phenomena in laser and powder-bed based layered manufacturing. CIRP Ann Manuf Technol 56(2):730-759

15. Fischer $\mathrm{P}$, Leber H, Romano V, Weber HP, Karapatis N, André C, Glardon R (2003) Microstructure of near infrared pulsed laser sintered Titanium samples. Appl Phys A 78:1219-1227

16. German RM (1996) Sintering theory and practice. Wiley, New York

17. Klocke F, Wagner C (2003) Coalescence behaviour of two metallic particles as base mechanism of selective laser sintering. CIRP Ann Manuf Technol 52(1):177-180

18. Tolochko NK, Mozzharov SE, Yadroitsev IA, Laoui T, Froyen L, Titov VI, Ignatiev MB (2004) Balling processes during selective laser treatment of powders. Rapid Prototyping J 10(2):78-87

19. Fischer P, Romano V, Weber HP, Karapatis NP, Boillat E, Glardon R (2003) Sintering of commercially pure Titanium powder with a Nd:YAG laser source. Acta Mater 51(6):16511662 